\title{
Molecular diagnosis of hepatocellular carcinoma: trends in biomarkers combination to enhance early cancer detection
}

\author{
Tiong Sun Chia, Kwong Fai Wong, John M. Luk \\ Arbele Limited, Hong Kong Science \& Technology Park, Shatin, New Territories, Hong Kong.
}

Correspondence to: Dr. John M. Luk, Rm 522, Biotech Center 2, 11W Science Park Ave, Hong Kong Science \& Technology Park, Shatin, New Territories, Hong Kong. E-mail: dr.johnluk@gmail.com

\begin{abstract}
How to cite this article: Chia TS, Wong KF, Luk JM. Molecular diagnosis of hepatocellular carcinoma: trends in biomarkers combination to enhance early cancer detection. Hepatoma Res 2019;5:9. http://dx.doi.org/10.20517/2394-5079.2018.112
\end{abstract}

Received: 3 Dec 2018 First Decision: 9 Jan 2019 Revised: 22 Feb 2019 Accepted: 25 Feb 2019 Published: 29 Mar 2019

Science Editor: Jin-Lin Hou Copy Editor: Cai-Hong Wang Production Editor: Huan-Liang Wu

\begin{abstract}
Despite of the advances in clinical imaging and applied research in proteomic biomarkers, liver cancer, especially hepatocellular carcinoma remains detected at the very late and advanced stages when curable treatments are unavailable and ineffective. In this regard, there are still huge unmet medical needs in developing and clinically validating those highpotential protein biomarkers preferably in liquid biopsy samples. This review provides a glimpse of emerging biomarkers together with detection tools and techniques which are potentially commercially available to the markets. We also discuss several diagnostic biomarkers having therapeutic potential for developing first-in-class medicines.
\end{abstract}

Keywords: Hepatocellular carcinoma, biomarkers, targets, $\alpha$-fetoprotein, cadherin-17, Yes-associated protein, AXL, Trop2

\section{INTRODUCTION}

Hepatocellular carcinoma (HCC) is the fifth most common cancer and the third leading cause of cancerrelated deaths worldwide ${ }^{[1]}$. The prognosis of HCC is generally poor, especially for late-stage malignancies, but a cure is possible if it is diagnosed at the early stages. In fact, 5-year survival for early stage HCC after curative treatments is as high as $70 \%{ }^{[2]}$. This highlights the uttermost importance of having a convenient, accurate and affordable diagnostic technique for early stage HCC.

\footnotetext{
(ㅇ) (1)

(C) The Author(s) 2019. Open Access This article is licensed under a Creative Commons Attribution 4.0 International License (https://creativecommons.org/licenses/by/4.0/), which permits unrestricted use, sharing, adaptation, distribution and reproduction in any medium or format, for any purpose, even commercially, as long as you give appropriate credit to the original author(s) and the source, provide a link to the Creative Commons license, and indicate if changes were made.
}

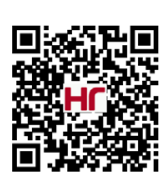


The current clinical diagnosis of early HCC is mainly based on medical imaging, including ultrasonography, computed tomography (CT) and magnetic resonance imaging. Early stage HCC is classified by having less than 4 tumour nodules with less than $3 \mathrm{~cm}$ in diameter ${ }^{[3]}$. The sensitivity and specificity for ultrasonography to pick up these tumour nodules are $60 \%$ and $97 \%$, respectively, while CT has sensitivity and specificity of $68 \%$ and $93 \%$, respectively ${ }^{[4]}$. There have been several attempts to increase the sensitivity by combining imaging with $\alpha$-fetoprotein (AFP) biomarker but with limited success so far, indicating the urgent need for new potential biomarkers ${ }^{[5,6]}$. Many patients have no access to diagnostic imaging due to the lack of necessary equipment and imaging specialists in local and regional hospitals.

In this review, clinically approved biomarker, such as AFP, will be discussed in detail followed by updates on other diagnostic biomarkers under development, including AXL, thioredoxin and golgi protein-73 (GP73). A few promising HCC targets that can be used as both a diagnostic and a therapeutic biomarkers, such as glypican 3 (GPC3), Yes-associated protein 1 (YAP1), trophoblast cell-surface antigen 2 (Trop2) and vasorin (VASN), will also be described. Nucleic acids-based biomarkers, such as non-coding RNA, are beyond the scope of this review and are covered elsewhere in this special issue.

\section{DIAGNOSTIC BIOMARKERS FOR HCC}

\section{AFP}

AFP is the most well studied biomarker for HCC and is also the first biomarker approved for HCC detection in liquid biopsy. It is a 591 amino acids glycoprotein encoded by the AFP gene on human chromosome 4 (4q13). AFP transports a variety of molecules, including fatty acids and bilirubins, across the body ${ }^{[7]}$. It is mainly produced by the visceral endoderm of the yolk sac and fetal liver during development ${ }^{[8]}$. The highest AFP plasma concentration is detected during week 12 to week 16 of a fetal life and subsequently declines to virtually undetectable after birth ${ }^{[9]}$. However, unusually high serum concentration of AFP is also detected in patients with $\mathrm{HCC}^{[10,11]}$.

Nonetheless, the use of AFP as a biomarker for HCC has been controversial ever since its discovery nearly half a century ago ${ }^{[12,13]}$. One study that evaluated AFP as a standalone HCC biomarker on 5,581 men in China exhibited sensitivity and specificity of $55.3 \%$ and $86.5 \%$, respectively ${ }^{[14]}$. Although more early stage HCCs were reported in the test group than in the control group, there was no survival benefit in the test group. Another study that evaluated 18,816 patients with chronic hepatitis B demonstrated that combining ultrasonography with AFP test in a biannual screening scheme reduced the mortality of HCC in the test group by $37 \%{ }^{[15]}$. However, given the high false positive rate and additional costs, some argued the practicality of recommending such a biannual screening scheme ${ }^{[5]}$. A systematic review of five trials conducted on patients with hepatitis C, a high risk group, between 1999 and 2002 concluded that AFP had limited ability to detect early HCC $^{[13]}$. The high false positive rate is not only because only $61 \%$ of HCC expresses AFP ${ }^{[16]}$, but also the fact that AFP expression is detected in other liver abnormalities such as cirrhosis and acute hepatitis ${ }^{[17]}$ and other tumours, including endodermal sinus tumour ${ }^{[18]}$ and gastrointestinal malignancies ${ }^{[19]}$.

AFP exists in three different glycoforms, namely AFP-L1, AFP-L2 and AFP-L3. Interestingly, AFP-L3 expression only increases in HCC but not in hepatitis or cirrhosis, suggesting that it could be a better HCC biomarker ${ }^{[20]}$. However, a trial using AFP-L3 as the sole biomarker on 372 patients with hepatitis C virus demonstrated sensitivity of only $37 \%$, despite a specificity of $92 \%^{[21]}$. In the same study, combining AFP-L3 with another biomarker, des-gamma-carboxy prothrombin increased the sensitivity to $61 \%$ but scarified the specificity down to $71 \%$. Another phase II study using the combo for early stage HCC reported sensitivity and specificity of $78 \%$ and $62 \%$, respectively ${ }^{[22]}$. The very low sensitivity is probably because AFP-L3 is minimally expressed and usually undetectable when the patients' AFP level is below $20 \mathrm{ng} / \mathrm{mL}$. Kagebayashi et al. ${ }^{[23]}$ utilized a microfluidic device in an attempt to detect low level of AFP-L3 in patient serum but reported 
Table 1. Performance of various HCC diagnostic biomarkers and tools

\begin{tabular}{|c|c|c|c|c|}
\hline Biomarker & Sensitivity (\%) & Specificity (\%) & Note & Ref. \\
\hline Ultrasonography & 60 & 97 & Meta-analysis on 14 studies & {$[4]$} \\
\hline CT & 68 & 93 & Meta-analysis on 14 studies & [4] \\
\hline \multirow[t]{7}{*}{ AFP } & 55 & 87 & $n=5,581$ & [14] \\
\hline & 66 & 82 & Early stage $\mathrm{HCC}, n=836$ & {$[22]$} \\
\hline & 59 & 89 & Early stage $\mathrm{HCC}, n=1,100$ & {$[47]$} \\
\hline & 35 & 88 & Meta-analysis on 19 studies & {$[75]$} \\
\hline & $41-65$ & $80-94$ & Meta-analysis on 5 studies, cirrhotic patients & [139] \\
\hline & 97 & 40 & $n=100$ & [140] \\
\hline & 58 & 85 & $n=4,217$ & {$[52]$} \\
\hline \multirow[t]{2}{*}{ AFP-L3 } & 37 & 92 & $n=372$ & {$[21]$} \\
\hline & 57 & 64 & Detect using microfluidic device & [23] \\
\hline DCP & 61 & 70 & Early stage $\mathrm{HCC}, n=836$ & {$[22]$} \\
\hline \multirow[t]{2}{*}{ AFP-L3 + DCP } & 61 & 71 & $n=372$ & [21] \\
\hline & 78 & 62 & Early stage $\mathrm{HCC}, n=208$ & {$[22]$} \\
\hline$A X L$ & 71 & 73 & $n=584$ & {$[43]$} \\
\hline$A X L+A F P$ & 84 & 92 & $n=584$ & {$[43]$} \\
\hline Thioredoxin & 75 & 89 & Early stage $\mathrm{HCC}, n=1,100$ & {$[47]$} \\
\hline Thioredoxin + AFP & 83 & 94 & Early stage $\mathrm{HCC}, n=1,100$ & {$[47]$} \\
\hline GP73 & 75 & 97 & $n=4,217$ & {$[52]$} \\
\hline GP73 + AFP & 89 & 85 & $n=4,217$ & {$[52]$} \\
\hline \multirow[t]{2}{*}{ GPC3 } & 55 & 84 & Meta-analysis on 19 studies & {$[75]$} \\
\hline & 55 & 97 & Early stage HCC, meta-analysis on 19 studies & {$[75]$} \\
\hline OPN & 75 & 62 & Early stage $\mathrm{HCC}, n=312$ & [126] \\
\hline SCCA & 84 & 49 & $n=961$ & [141] \\
\hline Annexin A2 & 83 & 68 & Early stage $\mathrm{HCC}, n=224$ & [142] \\
\hline Annexin A2 + AFP & 87 & 68 & Early stage $\mathrm{HCC}, n=224$ & [142] \\
\hline SUPAR & 76 & 90 & $n=267$ & [143] \\
\hline MDK & 93 & 83 & $n=100$ & [140] \\
\hline
\end{tabular}

CT: computed tomography; AFP: $\alpha$-fetoprotein; GPC3: glypican 3; MDK: Midkine; OPN: osteopontin; SCCA: squamous cell carcinoma antigen; suPAR: soluble urokinase plasminogen activator receptor; DCP: des-gamma-carboxy prothrombin; HCC: hepatocellular carcinoma

sensitivity and specificity of only $57 \%$ and $64 \%$, respectively. Comparing AFP-L3 with AFP, Marrero et al. ${ }^{[22]}$ concluded that AFP was more sensitive than AFP-L3 for detecting early HCC. Taken together, these results suggest that AFP-L3, despite having higher specificity, is inferior than AFP as an HCC biomarker. The low sensitivity of AFP encourages combining AFP with other biomarkers that are significantly overexpressed in HCC [Table 1]. Three of these biomarkers that have performed extraordinarily when used in combination with AFP are AXL, thioredoxin and GP73.

\section{AXL}

AXL is a receptor tyrosine kinase that is expressed in a number of malignancies, including $\mathrm{HCC}^{[24]}$, lung cancer $^{[25]}$, ovarian cancer ${ }^{[26]}$, colon cancer ${ }^{[27]}$, breast cancer ${ }^{[28]}$ and pancreatic ductal adenocarcinoma ${ }^{[29]}$ [Figure 1]. AXL is stimulated by the vitamin K-dependent protein encoded by growth-arrest-specific gene 6. Stimulated AXL in turn activates the PI3K-AKT-mTOR, MEK-ERK, NF- $\mathrm{B}$ and JAK/STAT signaling pathways that lead to tumour growth, immune escape and drug resistance ${ }^{[30-35]}$. AXL is also expressed in normal bone marrow stroma and myeloid cells to clear apoptotic material, suppress inflammatory responses and control natural killer cell activity ${ }^{[36,37]}$. Loss of AXL, therefore, leads to inflammation and autoimmunity ${ }^{[38,39]}$. AXL is a key downstream target that drives YAP-dependent oncogenic functions ${ }^{[40]}$. Knocking down AXL by RNAi decreased the ability of YAP-expressing MIHA and the primary HCC cell line to proliferate and invade. Furthermore, AXL also serves as a putative entry receptor for Zika Virus, Ebola Virus and West Nile Virus to infect the host cells ${ }^{[41]}$. Activated AXL undergoes proteolytic processing to yield a soluble protein that can be detected in the serum ${ }^{[42]}$. Detection of very early HCC (i.e., BCLC stage 0) by soluble AXL (sAXL) 


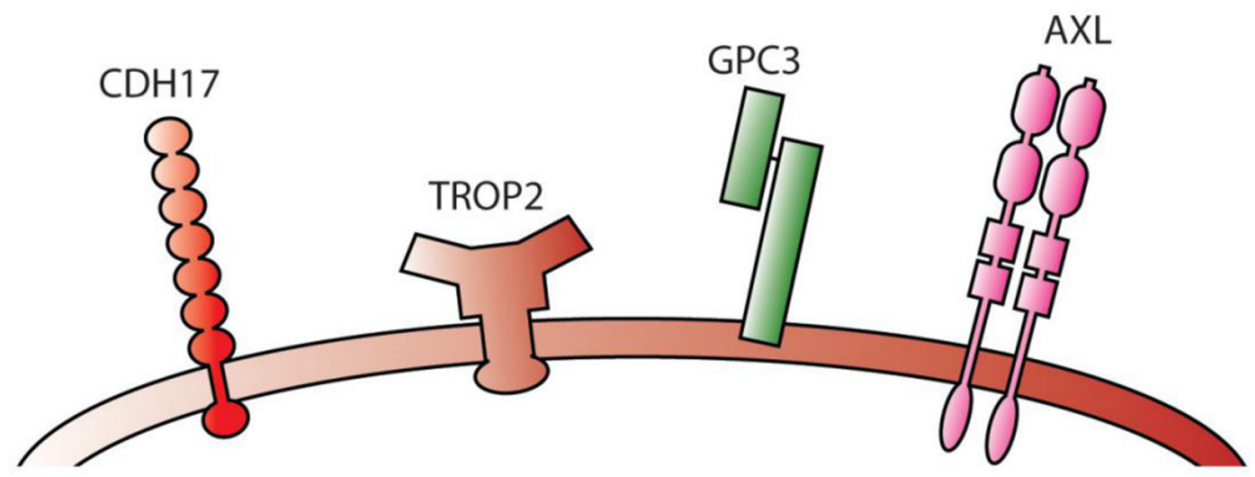

Figure 1. Cartoon depicting structures of cadherin-17 (CDH17), Trop2, glypican 3 (GPC3) and AXL

showed an area under the curve (AUC) of 0.848 upon receiver operating characteristic curve analysis. The sensitivity and specificity of the detection was $76.9 \%$ and $69.2 \%$, respectively. The accuracy of the detection was increased to 0.936 by the combined use of sAXL and AFP. Interestingly, sAXL combined with AFP could differentiate very early HCC from liver cirrhosis with an accuracy of 0.901 , of which the sensitivity and specificity was $88.5 \%$ and $76.7 \%$, respectively ${ }^{[43]}$. Nevertheless, multicenter clinical studies are needed to validate these findings.

\section{Thioredoxin}

Thioredoxin, together with thioredoxin reductase, forms a ubiquitous oxidoreductase system that plays an important role in regulating intracellular redox environment, controlling cellular proliferation and providing defense mechanism against oxidative stress ${ }^{[44]}$. Thioredoxin expression is detected in HCC, nonsmall cell lung cancer and colorectal cancer ${ }^{[45,46]}$. It is generally associated with a more aggressive tumour phenotype, poor prognosis and a lower survival rate. As a sole early stage HCC biomarker, Li et al. ${ }^{[4]}$ found that thioredoxin (sensitivity, 75\%; specificity, 89\%) surprisingly outperformed AFP (sensitivity, 70\%; specificity, 79\%) in their study. When used in combination, they could detect early HCC with an impressive sensitivity and specificity of $83 \%$ and $94 \%$, respectively. This supports the idea that an ideal combination of biomarkers can outperform a single biomarker in giving both lower false positive and false negative rates.

\section{GP73}

GP73 is a 400 amino acid, type II Golgi-specific membrane glycoprotein normally expresses on epithelial cells of liver and kidney ${ }^{[48]}$. GP73 resides within the cis-Golgi complex but it can be secreted into the extracellular space by cleavage at the proprotein convertase site ${ }^{[49]}$. In fact, soluble GP73 was detected in the medium cultured with HeLa, foreskin fibroblasts (HCA) and osteosarcoma (MG63) cell lines, suggesting that it may have some functions in the extracellular environment ${ }^{[50]}$. A number of studies noted elevated level of serum GP73 in HCC patients ${ }^{[4,51]}$. Mao et al.$^{[52]}$ compared serum GP73 and AFP biomarkers in 4,217 subjects with a mixture of healthy adults, HBV carriers and patients with cirrhosis, HCC or others cancers. They found GP73 to be a superior biomarker (sensitivity: 75\%, specificity: 97\%) than AFP (sensitivity 58\%, specificity $85 \%$ ). The combination of both biomarkers improved the sensitivity further to $89 \%$ but with a drop-in specificity down to $85 \%$.

\section{Annexin A2}

Annexin A2 (ANXA2), a member of the annexin family, is a $36-\mathrm{kDa}$ calcium-dependent phospholipidbinding protein that plays a role in immune responses, phospholipase A2 regulation and anti-inflammation. The serum ANXA2 was found to be elevated in HCC patients $(n=50)$ as compared with patients with chronic disease $(n=30)$ or healthy subjects $(n=20)$ by ELISA ${ }^{[53]}$. In the same study, follistatin, a potential serological HCC biomarker, was found elevated in both HCC patients and patients with chronic liver 
disease. The authors highlighted the superiority of ANXA2 over follistatin but given the low number of patient samples, more comprehensive studies are required to draw a conclusion.

\section{BIOMARKER COMBINATIONS FOR HCC DIAGNOSIS}

In addition to individual biomarkers and those combined with AFP, biomarker combinations for the diagnosis of early HCC have also been extensively studied. Cytokeratin-1 (CK-1) and nuclear matrix protein-52 (NMP-52) elevated in sera of patients with HCC. Combination of CK-1, NMP-52 and AFP showed an AUC of 0.9 for identifying HCC with $80 \%$ sensitivity and $92 \%$ specificity. More interestingly, this triple combination could differentiate HCC from liver fibrosis with an AUC of 0.94 with $80 \%$ sensitivity and $92 \%$ specificity ${ }^{[54]}$. Epithelial membrane antigen and fibronectin, of which the serum levels were increased in HCC, when in conjunction with total bilirubin and APF, could identify HCC from cirrhosis with an AUC of 0.92 with $89 \%$ sensitivity and $85 \%$ specificity ${ }^{[55]}$. Combined use of plasma protein with immune cells in HCC diagnosis has been published as well. A combination of plasma Dickkopf-1, Tie2-expressing monocytes and AFP yielded an AUC of 0.833 for HCC diagnosis ${ }^{[56]}$. The clinical utility of these biomarker combinations undoubtedly requires further validation in independent cohorts.

\section{Diagnostic biomarkers with therapeutic potential}

Although early diagnosis of HCC should translate into better overall survival, Chen et al. ${ }^{[14]}$ did not find this link in their study, citing lack of effective treatment as the main reason. Biomarkers that can serve as both a diagnostic tool and a therapeutic target would, undoubtedly, be more beneficial to the patients, as the diagnostic results can immediately assist physicians in planning treatment regimen. A number of promising biomarkers of this type are discussed below.

\section{GPC3}

GPC3 is a member of heparin sulfate proteoglycan family, which is bound to the cell membrane by a glycosyl-phosphatidylinositol (GPI) anchor ${ }^{[57]}$. A total of 6 glypicans have been identified to date, namely GPC1 to GPC6, and they are predominantly expressed during development ${ }^{[58]}$. The amino acid sequence homologies amongst glypicans are low but the location of 14 cysteine residues are conserved, indicating that they may share similar high-dimension structures. The location of the heparin sulfate insertion sites of the glypicans appears to be restricted to the $\mathrm{C}$ terminus, putting the heparin sulfate chains near to the cell membrane ${ }^{[58]}$. GPC3 is a 580 amino acid protein encoded by the GPC3 gene located on human chromosome $\mathrm{X}$ (Xq26). Despite being a cell membrane protein, GPC3 is cleaved by the Notum lipase at the GPI anchor and released into the serum ${ }^{[59]}$, making it easy for clinical detection. GPC3 is frequently upregulated in HCC and melanoma ${ }^{[60]}$. By fixed tissue staining, GPC3 expression was detected in up to $72 \%$ of samples from patients with HCC, but not in healthy subjects or patients with benign liver diseases ${ }^{[59]}$. The mRNA level of GPC3 was also upregulated in $\mathrm{HCC}^{[61,62]}$. Moreover, at least three independent groups reported significant elevation of serum GPC3 in HCC but not hepatitis ${ }^{[63-65]}$. Taken together, the data strongly suggestGPC3 to be an attractive serum and histochemical biomarker for HCC.

GPC3 can stimulate Wnt signaling through canonical and non-canonical pathways, which are initiated by Wnt ligands and Frizzled receptors ${ }^{[66]}$. Given that Wnt proteins bind to heparin sulfate, it was suggested that GPC3 acts as a facilitator of the interaction between Wnt ligands and Frizzled receptors ${ }^{[6,66]}$. GPC3 may promote tumourigenesis by facilitating canonical Wnt signal activation, which is frequently observed in $\mathrm{HCC}^{[65,68,69]}$. In contrast, GPC3 expression is downregulated in breast and ovarian cancers, suggesting that the functions of GPC3 may be tissue-specific ${ }^{[70-72]}$. Indeed, GPC3 is found to be a negative regulator of Hedgehog signaling pathway. Downregulation of GPC3 causes hyperactive Hedgehog signaling, which promotes ovarian and breast cancer progression ${ }^{[73]}$. Filmus and Capurro ${ }^{[67]}$ proposed that GPC 3 may exert different functions depending on cell types. In tissues that proliferate mainly via Hedgehog signaling, overexpression of GPC3 has an inhibitory effect on proliferation whereas in tissues where canonical Wnt signaling exerts a dominant influence, upregulation of GPC3 promotes cell proliferation. 
As a HCC diagnostic biomarker, GPC3 outperformed AFP in a number of independent studies. Tangkijvanich et al. ${ }^{[74]}$ reported sensitivity of $56 \%$ for GPC3 while AFP stood at $33 \%$. Interestingly, GPC3 overexpression did not correlate with AFP level, tumour size or stage of HCC but was significantly associated with the presence of viral hepatitis markers. A meta-analysis of 19 studies reported the superior sensitivity for GPC3 (pooled sensitivity, 55\%; pooled specificity, 84\%) over AFP (pooled sensitivity, 35\%; pooled specificity, $88 \%)^{[75]}$. Notably, the specificity for GPC3 was significantly higher if the analysis focused only on early HCC (pooled sensitivity 97\%).

The potential of GPC3 goes well beyond being a diagnostic biomarker. GPC3 is an oncofetal antigen, a protein that is predominantly expressed in cancer and during fetal development. Murine model injected with GPC3 transgenic colon cell line showed that GPC3 was able to elicit T-cell mediated tumour rejection without autoimmunity ${ }^{[76]}$. Similar results were reported using highly metastatic mouse melanoma ${ }^{[77]}$. Importantly, the anti-tumour effects appeared to be mediated by both $\mathrm{CD} 4^{+}$and $\mathrm{CD} 8^{+} \mathrm{T}$ cells, which are essential for optimal anti-tumour response. $\mathrm{CD}^{+}{ }^{+} \mathrm{T}$ cells have a broad role in orchestrating host anti-tumour responses, such as secreting cytokines to enhance cytotoxic $\mathrm{T}$ cell response, activating eosinophils and tumouricidal macrophages and secreting granulocyte/macrophage colony-stimulating factor. These results encourage development of immunotherapy targeting against the tumor-specific GPC3 isoform.

A phase I clinical study of a GPC3-derived peptide vaccine for 33 advanced HCC patients demonstrated that the vaccine was well-tolerated ${ }^{[78]}$. Most patients had only grade I and grade II side effects. Four patients developed grade III hematological adverse events but were likely due to disease progression rather than the vaccine. In terms of efficacy, 1 patient showed partial response while 19 patients had stable disease 2 months after initiation of treatment. Given the favorable safety profile, it is rational to target GPC3 with other therapies, such as adoptive cell transfer. Along this line of thinking, there have been several Phase 1 clinical studies of chimeric antigen receptor (CAR)-T trials directed against the GPC3 antigen in HCC patients.

Recently, a phase I clinical trial of anti-GPC CAR-T cells was conducted on Chinese patients $(n=13)$ with refractory or relapsed $\mathrm{GPC}^{+}{ }^{+} \mathrm{HCC}$. The 3rd generation CAR-T was engineered with $\mathrm{CD} 28,4-1 \mathrm{BB}$ and $\mathrm{CD} 3 \zeta$ downstream signaling domains ${ }^{[79]}$. No dose-limiting toxicities were identified and only one patient experienced grade 3 fever $^{[80]}$. Without lymphodepletion, none of the five patients responded to the treatment but with lymphodepletion, $4 / 6(67 \%)$ clinical response was reported. The authors concluded that the anti$\mathrm{GPC} 3 \mathrm{CAR}-\mathrm{T}$ treatment is safe and tolerable.

A bispecific T cell-redirecting antibody that binds both GPC3 and $\mathrm{CD} 3$ is also under active development by Chugai Pharmaceutical (a Roche subsidiary). Early studies on animal models showed that the GPC3/ $\mathrm{CD} 3$ bispecific antibody showed anti-tumour efficacy against various GPC3-positive xenografts including liver tumours ${ }^{[81]}$. This bispecific antibody is now being investigated in a phase I clinical trial on patients with GPC3 positive advanced solid tumours (NCT02748837).

\section{Cadherin-17}

Cadherin-17 (CDH17) is a calcium-dependent cell adhesion molecule that belongs to the $7 \mathrm{D}$-cadherin superfamily, characterized by the presence of 7 cadherin-like ectodomains followed by a short cytoplasmic tail $^{[82]}$. It is normally present in fetal liver and gastrointestinal tract during embroyogenesis, hence the name liver-intestinal cadherin (LI cadherin). It is a peptide transporter and plays an important role during embroyonic gastrointestinal development ${ }^{[83,84]}$. CDH17 expression was reported in normal human colon, intestine and pancreas but not normal liver and stomach ${ }^{[85-89]}$. However, the overexpression of $\mathrm{CDH} 17$ was observed in HCC as well as breast, ductal pancreatic, colorectal and gastric cancers ${ }^{[90-93]}$. The upregulation was associated with malignant transformation of these cancers. Knock-down of CDH17 by RNAi inhibited proliferation of primary and metastatic HCC cell lines in vitro and in vivo ${ }^{[94]}$. This anti-tumour effect was likely due to inactivation of Wnt signaling pathway because CDH17-knockdown HCC tumours 
showed re-localization of $\beta$-catenin to cytoplasm, concomitant reduction in cyclin D1 and increase in tumour suppressor retinoblastoma. In addition, $\mathrm{CDH} 17$ was reported as an useful diagnostic marker for adenocarcinomas of the digestive system ${ }^{[95]}$. It was also associated with bone marrow metastasis of breast cancer $^{[96]}$ and liver metastasis of colorectal cancer ${ }^{[93]}$.

CDH17 expression was upregulated by 2.5 to 800 folds in over $80 \%$ HCC but not in healthy liver, making it an attractive diagnostic and therapeutic biomarker for $\mathrm{HCC}^{[88]}$. Half of the $\mathrm{CDH} 17^{+}$HCC patients have gained genomic copy of this gene. Importantly, alternately spliced mRNA transcripts, characterized by loss of exon 7, were reported in roughly half of the HCC patient specimens. The splicing introduced a premature stop codon in the open-reading frame and resulted in a truncated $\mathrm{CDH} 17$ protein. It was speculated that overexpression of the truncated variant may act as a dominant inhibitor of wild-type CDH17, thereby enhancing tumour invasion. In consistent to this speculation, expression of this variant $\mathrm{CDH} 17$ was strongly associated with poorer overall survival, higher risk of relapse and venous infiltration after hepatectomy. The spliced transcripts were only detected in HCC samples but not normal liver samples, implying that the splicing is likely to be an aberrant cancerous event rather than a normal splicing phenomenon. Importantly, an antibody against the RGD motif of $\mathrm{CDH} 17$ has shown promising anti-tumour effects against metastatic colon cancer and melanoma, suggesting that it is likely to be effective against $\mathrm{HCC}^{[97]}$.

\section{YAP1}

YAP1, also known as YAP or YAP65, is an oncogene encoded by the YAP1 gene located on human chromosome $11(11 \mathrm{q} 22)^{[98]}$. It is a downstream nuclear effector of the Hippo signaling pathway, which is important for development, cell proliferation, repair and homeostasis ${ }^{[99]}$. Given its importance in cell proliferation, YAP1 knockout mice showed development arrest and died prematurely ${ }^{[100]}$. Studies on the Drosophila Yorkie (Yki) protein, an ortholog of YAP1, suggested that YAP1 is negatively regulated by the Hippo pathway ${ }^{[101]}$. Inactivation of Hippo pathways leads to accumulation of Yki proteins in the nucleus and upregulation of genes associated with cell survival and proliferation, including $c y c E$, diap1/thread and bantam $^{[102]}$. In mammalian cells, overexpression of YAP1 caused aberrant expression of genes associated with cell proliferation, anti-apoptosis, survival and migration, such as CTGF, CCND1, ITGB2 and BCL2L $1^{[103]}$.

Analysis on 177 HCC samples by immunohistochemistry, Western blot analysis and RT-PCR showed that approximately $62 \%$ of both YAP protein and mRNA were upregulated as compared to adjacent nontumour tissues ${ }^{[104]}$. The YAP proteins were mainly accumulated in the tumour nucleus. In an independent study, Zhao et al ${ }^{[101]}$ also reported YAP overexpression in 63 of the 115 HCC samples tested by tissue microarray. Similar results were reported in non-small lung cell cancer, suggesting that YAP may have broad implications in different solid cancers ${ }^{[105]}$. Importantly, YAP expression was associated with poorer tumour differentiation, high serum AFP level and lower overall survival rate, indicating that it may be used as an independent prognostic marker ${ }^{[104]}$.

Both YAP and transcriptional co-activator with PDZ-binding motif (TAZ) are downstream effectors of Hippo pathway. Hayashi et al ${ }^{[106]}$ reported that knocking down TAZ, under normal condition, inhibited cell growth in HCC. However, treating the TAZ knockdown cells with 5-fluorouracil induced YAP expression that conferred chemoresistance. The drug resistance was not observed when both TAZ and YAP were knockdown, suggesting that a shift to predominantly YAP expression when TAZ was depleted led to chemoresistance and tumourigenecity. The authors concluded that targeting both YAP and ZAP is essential for a complete anti-tumour response. Given that YAP expression is an early event in HCC tumourigenesis and its expression is critical to chemoresistance and proliferation of malignant hepatocytes, YAP is a promising HCC target for therapeutic intervention.

The oncogenic activity of YAP depends on its interaction with transcriptional enhancer activation domain family member 1 (TEAD1) that resides in the nucleus and therefore, disrupting YAP-TEAD1 interaction is 
believed to have anti-cancer efficacy in YAP positive tumours ${ }^{[107]}$. YAP-like peptides occupying the interface 3 on YAP/TEAD complex were shown able to block YAP-TEAD1 interaction ${ }^{[108]}$. Small-molecule inhibitors (SMIs) targeting the same interface were recently shown to suppress the expression of YAP target genes ${ }^{[109]}$. Whether these peptides or SMIs would inhibit tumour growth in vivo however remains to be investigated.

\section{Trop2}

Trop2, also known as tumour-associated calcium signal transducer 2 (TACSTD2) or epithelial glycoprotein-1 antigen, is a calcium signal transducer encoded by the TACSTD2 gene located on human chromosome 1 (1p32.1). Trop2 is a cell surface glyprotein that is associated with regulation of cyclin D1 and protein kinase C levels. Trop2 stimulates the expression of cyclin D1 and cyclin E via the mitogen-activated protein kinase/ extracellular signal-regulated kinase (MAPK/ERK) pathway to promote cell proliferation ${ }^{[110]}$. Numerous reports have confirmed that Trop2 is an oncogene associated with tumour development, progression and metastasis in various cancers, including pancreatic cancer ${ }^{[111]}$, squamous cell carcinoma ${ }^{[12]}$, gastric carcinoma $^{[113]}$, hilar cholangiocarcinoma ${ }^{[114]}$, colorectal cancer $^{[115]}$, cervical cancer ${ }^{[116]}$, ovarian carcinoma ${ }^{[117]}$, gallbladder cancer ${ }^{[118]}$ and breast cancer ${ }^{[119]}$. Unsurprisingly, Trop2 overexpression is often associated with poor cancer prognosis. A recent gene network analytic study found aberrant expression of Trop2 in HCC ${ }^{[120]}$. Given that Trop2 is an oncogene in many cancers, it is speculated that it may be a potential biomarker candidate and a therapeutic target for HCC.

\section{VASN}

VASN is a cell surface and secreted protein that modulates the arterial response to injury by inhibiting the TFG- $\beta$ signaling pathway ${ }^{[121,122]}$. It was identified as a potential HCC biomarker using a subtractive EMSASELEX strategy from AFP negative serum of HCC patients with secondary metastasis ${ }^{[123]}$. VASN expression can be detected in aorta, kidney, placenta, brain, heart, liver, lung and skeletal muscle tissues. It was highly expressed in HCC samples $(n=100)$ but not in normal liver $(n=97)$ or hepatitis samples $(n=129)$, as verified by both Western blotting and quantitative PCR. This high VASN expression appeared to be negatively regulated by microRNAs miR145 and miR146a. Downregulation of these microRNAs led to overexpression of VASN, which promoted cell proliferation and migration and inhibited apoptosis. As a membrane protein, VASN has the potential to be a therapeutic target.

\section{Osteopontin}

Osteopontin (OPN), a matrix glycoprotein secreted by a wide variety of cell types, has also emerged as a biomarker with diagnostic potential ${ }^{[124]}$. Plasma level of OPN in patients with HCC was significantly higher than in or healthy subjects or patients with chronic liver diseases ${ }^{[125]}$. In a prospective study on 22 patients who developed HCC during follow-up, OPN was elevated in plasma one year before cancer diagnosis ${ }^{[126]}$. A meta-analysis on 12 published studies showed that the sensitivity in HCC diagnosis was higher than that of AFP (OPN, 0.813; AFP, 0.639) ${ }^{[127]}$. Plasma OPN could be used to differentiate HCC from other nonmalignant liver diseases including chronic hepatitis $\mathrm{C}$, cirrhosis, and nonalcoholic fatty liver disease ${ }^{[128]}$. Importantly,serum OPN was associated with dismal overall survivals of patients with HCC with a hazard ratio of $2.38^{[129]}$.

In addition to its diagnostic value, OPN can be a potential therapeutic target for HCC treatment. Antiviral therapy suppressed early progression of hepatitis B-related HCC by modulating the expression of OPN in patients ${ }^{[130]}$. Knockdown of OPN using RNA interference suppressed in vivo growth and lung metastasis of liver cancer xenograft in mice ${ }^{[131]}$. Monoclonal antibodies (mAbs) against OPN have been reported to demonstrate anti-cancer effects in animal models. An antibody named AOM1, which abrogated the integrin binding of OPN, was illustrated to suppress the in vivo of Kras-mutant non-small cell lung adenocarcinoma in mice ${ }^{[132]}$. Hu1 $\mathrm{A} 12$, another OPN $\mathrm{mAb}$ that bound to the calcium binding domain of OPN, was demonstrated to inhibit primary tumor growth and spontaneous metastasis in a mouse lung metastasis 
model of human breast cancer ${ }^{[133]}$. There studies strongly support OPN as a potential target for the antibodybased cancer therapy, although the anti-cancer efficacy of OPN mAbs in HCC has remained to be studied.

\section{CONCLUSION}

HCC is an extremely difficult to treat cancer, which generally involves multiple pathologic complications includinghepatitis, metabolic (NASH and diabetic), fibrotic and cirrhotic diseased conditions in addition to the notorioustumor burden. As a result, both the current diagnosis and treatments of HCC remain largely ineffective. Therefore, bringing new biomarkers and innovative treatments to the patients are in critical demand. With the recent advent of cancer immunotherapy, it is more than ever necessary to find tumourspecific biomarkers as therapeutic targets. One of the major challenges in immunotherapy on solid tumours is the extreme scarcity of highly specific targets ${ }^{[134]}$. Failure to find such a target has led to not only ineffective treatment but also high toxicities and even deaths in clinical trials ${ }^{[135-138]}$. Despite being extremely rare and highly challenging, fortunately, recent advances in next-generation sequencing and high-throughput technologies would, undoubtedly, accelerate discovery of such biomarkers and make progress for the diagnosis and treatment of HCC.

\section{DECLARATIONS}

\section{Authors' contributions}

Wrote the manuscript: Chia TS, Wong KF, Luk JM

Reviewed the manuscript: Luk JM

\section{Availability of data and materials}

Not applicable.

\section{Financial support and sponsorship}

Chia TS and Wong KF are partly supported by the Postdoctoral Hub Programme of the Innovation and Technology Commission of the Government of HKSAR.

\section{Conflicts of interest}

All authors declared that there are no conflicts of interest.

\section{Ethical approval and consent to participate}

Not applicable.

\section{Consent for publication}

Not applicable.

\section{Copyright}

(C) The Author(s) 2019.

\section{REFERENCES}

1. Torre LA, Bray F, Siegel RL, Ferlay J, Lortet-Tieulent J, et al. Global cancer statistics, 2012. CA Cancer J Clin 2015;65:87-108.

2. Siegel R, Naishadham D, Jemal A. Cancer statistics, 2013. CA Cancer J Clin 2013;63:11-30.

3. Bruix J, Reig M, Sherman M. Evidence-based diagnosis, staging, and treatment of patients with hepatocellular carcinoma. Gastroenterology 2016;150:835-53.

4. Colli A, Fraquelli M, Casazza G, Massironi S, Colucci A, et al. Accuracy of ultrasonography, spiral CT, magnetic resonance, and alpha-fetoprotein in diagnosing hepatocellular carcinoma: a systematic review. Am J Gastroenterol 2006;101:513-23.

5. Bruix J, Reig M, Sherman M. Evidence-based diagnosis, staging, and treatment of patients with hepatocellular carcinoma. Gastroenterology 2016;150:835-53.

6. Tsuchiya N, Sawada Y, Endo I, Saito K, Uemura Y, et al. Biomarkers for the early diagnosis of hepatocellular carcinoma. World J 
Gastroenterol 2015;21:10573-83.

7. Mizejewski GJ. Alpha-fetoprotein structure and function: relevance to isoforms, epitopes, and conformational variants. Exp Biol Med 2001;226:377-408.

8. Gitlin D, Perricelli A, Gitlin JD. The presence of serum alphafetoprotein in sharks and its synthesis by fetal gastrointestinal tract and liver. Comp BiochemPhysiol B 1973;46:207-15.

9. Debruyne EN, Delanghe JR. Diagnosing and monitoring hepatocellular carcinoma with alpha-fetoprotein: new aspects and applications. Clin Chim Acta 2008;395:19-26.

10. Chayvialle JA, Ganguli PC. Radioimmunoassay of alpha-fetoprotein in human plasma. Lancet 1973;1:1355-7.

11. Waldmann TA, McIntire KR. The use of a radioimmunoassay for alpha-fetoprotein in the diagnosis of malignancy. Cancer 1974;34:1510-5

12. Chayvialle JA, Ganguli PC. Radioimmunoassay of alpha-fetoprotein in human plasma. Lancet 1973;1:1355-7.

13. Lederle FA, Pocha C. Screening for liver cancer: the rush to judgment. Ann Intern Med 2012;156:387-9.

14. Chen JG, Parkin DM, Chen QG, Lu JH, Shen QJ, et al. Screening for liver cancer: results of a randomized controlled trial in Qidong, China. J Med Screen 2003;10:204-9.

15. Zhang BH, Yang BH, Tang ZY. Randomized controlled trial of screening for hepatocellular carcinoma. J Cancer Res Clin Oncol 2004;130:417-22.

16. Muguti G, Tait N, Richardson A, Little JM. Alpha-fetoprotein expression in hepatocellular carcinoma: a clinical study. J Gastroenterol Hepatol 1992;7:374-8.

17. Chu CW, Hwang SJ, Luo JC, Lai CR, Tsay SH, et al. Clinical, virologic, and pathologic significance of elevated serum alphafetoprotein levels in patients with chronic hepatitis C. J Clin Gastroenterol 2001;32:240-4.

18. Talerman A, Haije WG, Baggerman L. Serum alphafetoprotein (AFP) in patients with germ cell tumors of the gonads and extragonadal sites: correlation between endodermal sinus (yolk sac) tumor and raised serum AFP. Cancer 1980;46:380-5.

19. Ucar E, Semerci E, Ustun H, Yetim T, Huzmeli C, et al. Prognostic value of preoperative CEA, CA 19-9, CA 72-4, and AFP levels in gastric cancer. Adv Ther 2008;25:1075-84.

20. Li D, Mallory T, Satomura S. AFP-L3: a new generation of tumor marker for hepatocellular carcinoma. Clin Chim Acta 2001;313:15-9.

21. Sterling RK, Jeffers L, Gordon F, Venook AP, Reddy KR, et al. Utility of Lens culinaris agglutinin-reactive fraction of alphafetoprotein and des-gammacarboxy prothrombin, alone or in combination, as biomarkers for hepatocellular carcinoma. Clin Gastroenterol Hepatol 2009;7:104-13.

22. Marrero JA, Feng Z, Wang Y, Nguyen MH, Befeler AS, et al. Alpha-fetoprotein, des-gamma carboxyprothrombin, and lectinbound alpha-fetoprotein in early hepatocellular carcinoma. Gastroenterology 2009;137:110-8.

23. Kagebayashi C, Yamaguchi I, Akinaga A, Kitano H, Yokoyama K, et al. Automated immunoassay system for AFP-L3\% using on-chip electrokinetic reaction and separation by affinity electrophoresis. Anal Biochem 2009;388:306-11

24. Reichl P, Fang M, Starlinger P, Staufer K, Nenutil R, et al. Multicenter analysis of soluble Axl reveals diagnostic value for very early stage hepatocellular carcinoma. Int J Cancer 2015;137:385-94.

25. Zhang Z, Lee JC, Lin L, Olivas V, Au V, et al. Activation of the AXL kinase causes resistance to EGFR-targeted therapy in lung cancer. Nat Genet 2012;44:852-60.

26. Rankin EB, Fuh KC, Taylor TE, Krieg AJ, Musser M, et al. AXL is an essential factor and therapeutic target for metastatic ovarian cancer. Cancer Res 2010;70:7570-9.

27. Dunne PD, McArt DG, Blayney JK, Kalimutho M, Greer S, et al. AXL is a key regulator of inherent and chemotherapy-induced invasion and predicts a poor clinical outcome in early-stage colon cancer. Clin Cancer Res 2014;20:164-75.

28. D'Alfonso TM, Hannah J, Chen Z, Liu Y, Zhou P, et al. Axl receptor tyrosine kinase expression in breast cancer. J Clin Pathol 2014;67:690-6.

29. Song X, Wang H, Logsdon CD, Rashid A, Fleming JB, et al. Overexpression of receptor tyrosine kinase Axl promotes tumor cel invasion and survival in pancreatic ductal adenocarcinoma. Cancer 2011;117:734-43.

30. Varnum BC, Young C, Elliott G, Garcia A, Bartley TD, et al. Axl receptor tyrosine kinase stimulated by the vitamin K-dependent protein encoded by growth-arrest-specific gene 6. Nature 1995;373:623-6.

31. Fridell YW, Jin Y, Quilliam LA, Burchert A, McCloskey P, et al. Differential activation of the Ras/extracellularsignal-regulated protein kinase pathway is responsible for the biological consequences induced by the Axl receptor tyrosine kinase. Mol Cell Biol 1996;16:135-45.

32. Tai KY, Shieh YS, Lee CS, Shiah SG, Wu CW. Axl promotes cell invasion by inducing MMP-9 activity through activation of NFkappaB and Brg-1. Oncogene 2008;27:4044-55.

33. Ruan GX, Kazlauskas A. Axl is essential for VEGF-A-dependent activation of PI3K/Akt. EMBO J 2012;31:1692-703.

34. Paccez JD, Vasques GJ, Correa RG, Vasconcellos JF, Duncan K, et al. The receptor tyrosine kinase Axl is an essential regulator of prostate cancer proliferation and tumor growth and represents a new therapeutic target. Oncogene 2013;32:689-98.

35. Hong CC1, Lay JD, Huang JS, Cheng AL, Tang JL, et al. Receptor tyrosine kinase AXL is induced by chemotherapy drugs and overexpression of AXL confers drug resistance in acute myeloid leukemia. Cancer Lett 2008;268:314-24.

36. Neubauer A, Fiebeler A, Graham DK, O’Bryan JP, Schmidt CA, et al. Expression of axl, a transforming receptor tyrosine kinase, in normal and malignant hematopoiesis. Blood 1994;84:1931-41.

37. Shieh YS, Lai CY, Kao YR, Shiah SG, Chu YW, et al. Expression of axl in lung adenocarcinoma and correlation with tumor progression. Neoplasia 2005;7:1058-64.

38. Li N, Liu Z, Zhang Y, Chen Q, Liu P, et al. Mice lacking Axl and Mer tyrosine kinase receptors are susceptible to experimental autoimmune orchitis induction. Immunol Cell Biol 2015;93:311-20.

39. Weinger JG, Brosnan CF, Loudig O, Goldberg MF, Macian F, et al. Loss of the receptor tyrosine kinase Axl leads to enhanced 
inflammation in the CNS and delayed removal of myelin debris during experimental autoimmune encephalomyelitis. J Neuroinflammation 2011;8:49.

40. Xu MZ, Chan SW, Liu AM, Wong KF, Fan ST, et al. AXL receptor kinase is a mediator of YAP-dependent oncogenic functions in hepatocellular carcinoma. Oncogene 2011;30:1229-40.

41. Gay CM, Balaji K, Byers LA. Giving AXL the axe: targeting AXL in human malignancy. Br J Cancer 2017;116:415-23.

42. Pinato DJ, Mauri FA, Lloyd T, Vaira V, Casadio C, et al. The expression of Axl receptor tyrosine kinase influences the tumour phenotype and clinical outcome of patients with malignant pleural mesothelioma. Br J Cancer 2013;108:621-8.

43. Reichl P, Fang M, Starlinger P, Staufer K, Nenutil R, et al. Multicenter analysis of soluble Axl reveals diagnostic value for very early stage hepatocellular carcinoma. Int J Cancer 2015;137:385-94.

44. Nordberg J, Arnér ES. Reactive oxygen species, antioxidants, and the mammalian thioredoxin system. Free Radic Biol Med 2001;31:1287-312.

45. Kakolyris S, Giatromanolaki A, Koukourakis M, Powis G, Souglakos J, et al. Thioredoxin expression is associated with lymph node status and prognosis in early operable non-small cell lung cancer. Clin Cancer Res 2001;7:3087-91.

46. Raffel J, Bhattacharyya AK, Gallegos A, Cui H, Einspahr JG, et al. Increased expression of thioredoxin-1 in human colorectal cancer is associated with decreased patient survival. J Lab Clin Med 2003;142:46-51.

47. Li J, Cheng ZJ, Liu Y, Yan ZL, Wang K, et al. Serum thioredoxin is a diagnostic marker for hepatocellular carcinoma. Oncotarget 2015;6:9551-63.

48. Yang J, Li J, Dai W, Wang F, Shen M, et al. Golgi protein 73 as a biomarker for hepatocellular carcinoma: a diagnostic meta-analysis. Exp Ther Med 2015;9:1413-20.

49. Jin D, Tao J, Li D, Wang Y, Li L, et al. Golgi protein 73 activation of MMP-13 promotes hepatocellular carcinoma cell invasion. Oncotarget 2015;6:33523-33.

50. Bachert C, Fimmel C, Linstedt AD. Endosomal trafficking and proprotein convertase cleavage of cis Golgi Protein GP73 produces marker for hepatocellular carcinoma. Traffic 2007;8:1415-24.

51. Kladney RD, Cui X, Bulla GA, Brunt EM, Fimmel CJ. Expression of GP73, a resident Golgi membrane protein, in viral and nonviral liver disease. Hepatology 2002;35:1431-40.

52. Mao Y, Yang H, Xu H, Lu X, Sang X, et al. Golgi protein 73 (GOLPH2) is a valuable serum marker for hepatocellular carcinoma. Gut 2010;59:1687-93.

53. El-Abd N, Fawzy A, Elbaz T, Hamdy S. Evaluation of annexin A2 and as potential biomarkers for hepatocellular carcinoma. Tumor Biol 2016;37:211-6.

54. Attallah AM, El-Far M, Malak CA, Omran MM, Shiha GE, et al. HCC-DETECT: a combination of nuclear, cytoplasmic, and oncofetal proteins as biomarkers for hepatocellular carcinoma. Tumor Biol 2015;36:7667-74.

55. Attallah AM, El-Far M, Abdel Malak CA, Farid K, Omran MM, et al. A simple diagnostic index comprising epithelial membrane antigen and fibronectin for hepatocellular carcinoma. Ann Hepatol 2015;14:869-80.

56. Mao L, Wang Y, Wang D, Han G, Fu S, et al. TEMs but not DKK1 could serve as complementary biomarkers for AFP in diagnosing AFP-negative hepatocellular carcinoma. PLoS One 2017;12: e0183880.

57. Filmus J. The contribution of in vivo manipulation of gene expression to the understanding of the function of glypicans. Glycoconj J 2002;19:319-23

58. Veugelers M, De Cat B, Ceulemans H, Bruystens AM, Coomans C, et al. Glypican-6, a new member of the glypican family of cell surface proteoglycans. J Biol Chem 1999;274:26968-77.

59. Traister A, Shi W, Filmus J. Mammalian Notum induces the release of glypicans and other GPI anchored proteins from the cell surface. Biochem J 2008;410:503-11.

60. Nakatsura T1, Kageshita T, Ito S, Wakamatsu K, Monji M, et al. Identification of glypican-3 as a novel tumor marker for melanoma. Clin Cancer Res 2004;10: 6612-21.

61. Hsu HC, Cheng W, Lai PL. Cloning and expression of a developmentally regulated transcript MXR7 in hepatocellular carcinoma: biological significance and temporospatial distribution. Cancer Res 1997;57:5179-84.

62. Zhu ZW, Friess H, Wang L, Abou-Shady M, Zimmermann A, et al. Enhanced glypican-3 expression differentiates the majority of hepatocellular carcinomas from benign hepatic disorders. Gut 2001;48:558-64.

63. Nakatsura T, Yoshitake Y, Senju S, Monji M, Komori H, et al. Glypican-3, overexpressed specifically in human hepatocellular carcinoma, is a novel tumor marker. Biochem Biophys Res Commun 2003;306:16-25.

64. Hippo Y, Watanabe K, Watanabe A, Midorikawa Y, Yamamoto S, et al. Identification of soluble NH2-terminal fragment of glypican-3 as a serological marker for early-stage hepatocellular carcinoma. Cancer Res 2004;64:2418-23.

65. Capurro MI, Xiang YY, Lobe C, Filmus J. Glypican-3 promotes the growth of hepatocellular carcinoma by stimulating canonical Wnt signaling. Cancer Res 2005;65:6245-54.

66. Filmus J, Capurro M, Rast J. Glypicans. Genome Biol 2008;9:224.

67. Filmus J, Capurro M. The role of glypican-3 in the regulation of body size and cancer. Cell Cycle 2008;7:2787-90.

68. Feitelson MA, Sun B, Tufan NLS, Liu J, Pan J, et al. Genetic mechanisms of hepatocarcinogenesis. Oncogene 2002;21:2593-604.

69. Kern MA, Breuhahn K, Schirmacher P. Molecular pathogenesis of human hepatocellular carcinoma. Adv Cancer Res 2002;67:112.

70. Xiang YY, Ladeda V, Filmus J. Glypican-3 expression is silenced in human breast cancer. Oncogene 2001;20:7408-12.

71. Lin H, Huber R, Schlessinger D, Morin PJ. Frequent silencing of the GPC3 gene in ovarian cancer cell lines. Cancer Res 1999;59:807-10.

72. Kim H, Xu GL, Borczuk AC, Busch S, Filmus J, et al. The heparan sulfate proteoglycan GPC3 is a potential lung tumor suppressor. Am J Resp Cell Mol Biol 2003;29:694-701.

73. Capurro MI, Xu P, Shi W, Li F, Jia A, et al. Glypican-3 inhibits hedgehog signaling during development by competing with Patched for Hedgehog binding. Dev Cell 2008;14:700-11. 
74. Tangkijvanich P, Chanmee T, Komtong S, Mahachai V, Wisedopas N, et al. Diagnostic role of serum glypican-3 in differentiating hepatocellular carcinoma from non-malignant chronic liver disease and other liver cancers. J Gastroenterol Hepatol 2010;25:129-37.

75. Jia X, Liu J, Gao Y, Huang Y, Du Z. Diagnosis accuracy of serum glypican-3 in patients with hepatocellular carcinoma: a systematic review with meta-analysis. Arch Med Res 2014;45:580-8.

76. Nakatsura T, Komori H, Kubo T, Yoshitake Y, Senju S, et al. Mouse homologue of a novel human oncofetal antigen, glypican-3, evokes T-cell-mediated tumor rejection without autoimmune reactions in mice. Clin Cancer Res 2004;10:8630-40.

77. Motomura Y, Senju S, Nakatsura T, Matsuyoshi H, Hirata S, et al. Embryonic stem cell-derived dendritic cells expressing glypican-3, a recently identified oncofetal antigen, induce protective immunity against highly metastatic mouse melanoma, B16-F10. Cancer Res 2006;66:2414-22.

78. Sawada Y, Yoshikawa T, Nobuoka D, Shirakawa H, Kuronuma T, et al. Phase I trial of a glypican-3-derived peptide vaccine for advanced hepatocellular carcinoma: immunologic evidence and potential for improving overall survival. Clin Cancer Res 2012;18:3686-96.

79. Gao H, Li K, Tu H, Pan X, Jiang H, et al. Development of T Cells Redirected to Glypican-3 for the Treatment of Hepatocellular Carcinoma. Clin Cancer Res 2014;20:6418.

80. Zhai B, Shi D, Gao H, Qi X, Jiang H, et al. A phase I study of anti-GPC3 chimeric antigen receptor modified T cells (GPC3 CAR-T) in Chinese patients with refractory or relapsed GPC3+ hepatocellular carcinoma (r/r GPC3+ HCC). J Clin Oncol 2017;35:3049.

81. Ishiguro T, Sano Y, Komatsu SI, Kamata-Sakurai M, Kaneko A, et al. An anti-glypican 3/CD3 bispecific T cell-redirecting antibody for treatment of solid tumors. Sci Transl Med 2017;9:eaal4291

82. Gessner R, Tauber R. Intestinal cell adhesion molecules. Liver-intestine cadherin. Ann N Y Acad Sci 2000;915:136-43.

83. Berndorff D, Gessner R, Kreft B, Schnoy N, Lajous-Petter AM, et al. Liver-intestine cadherin: molecular cloning and characterization of a novel Ca2+-dependent cell adhesion molecule expressed in liver and intestine. J Cell Biol 1994;125:1353-69.

84. Dantzig AH, Hoskins JA, Tabas LB, Bright S, Shepard RL, et al. Association of intestinal peptide transport with a protein related to the cadherin superfamily. Science 1994;264:430-3.

85. Wong BW, Luk JM, Ng IO, Hu MY, Liu KD, et al. Identification of liver-intestine cadherin in hepatocellular carcinoma--a potential disease marker. Biochem Biophys Res Commun 2003;311:618-24.

86. Grotzinger C, Kneifel J, Patschan D, Schnoy N, Anagnostopoulos I, et al. LI-cadherin: a marker of gastric metaplasia and neoplasia. Gut 2001;49:73-81.

87. Takamura M, Sakamoto M, Ino Y, Shimamura T, Ichida T, et al. Expression of liverintestine cadherin and its possible interaction with galectin-3 in ductal adenocarcinoma of the pancreas. Cancer Sci 2003;94:425-30.

88. Wang XQ, Luk JM, Leung PP, Wong BW, Stanbridge EJ, et al. Alternative mRNA splicing of liver intestine-cadherin in hepatocellular carcinoma. Clin Cancer Res 2005;11:483-9.

89. Takamura M, Ichida T, Matsuda Y, Kobayashi M, Yamagiwa S, et al. Reduced expression of liver-intestine cadherin is associated with progression and lymph node metastasis of human colorectal carcinoma. Cancer Lett 2004;212:253-9.

90. Wong BW, Luk JM, Ng IO, Hu MY, Liu KD, et al. Identification of liver intestine cadherin in hepatocellular carcinoma - a potentia disease marker. Biochem Biophys Res Commun 2003;311:618-24.

91. Hinoi T, Lucas PC, Kuick R, Hanash S, Cho KR, et al. CDX2 regulates liver intestine-cadherin expression in normal and malignant colon epithelium and intestinal metaplasia. Gastroenterology 2002;123:1565-77.

92. Park JH, Seol JA, Choi HJ, Roh YH, Choi PJ, et al. Comparison of cadherin-17 expression between primary colorectal adenocarcinomas and their corresponding metastases: the possibility of a diagnostic marker for detecting the primary site of metastatic tumour. Histopathology 2011;58:315-8.

93. Bartolome RA, Barderas R, Torres S, Fernandez-Acenero MJ, Mendes M, et al. Cadherin-17 interacts with a2b1 integrin to regulate cell proliferation and adhesion in colorectal cancer cells causing liver metastasis. Oncogene 2014;33:1658-69.

94. Liu LX, Lee NP, Chan VW, Xue W, Zender L, et al. Targeting cadherin-17 inactivates Wnt signaling and inhibits tumor growth in liver carcinoma. Hepatology 2009;50:1453-63.

95. Su MC, Yuan RH, Lin CY, Jeng YM. Cadherin-17 is a useful diagnostic marker for adenocarcinomas of the digestive system. Mod Pathol 2008;21:1379-86.

96. Okada T, Kurabayashi A, Akimitsu N, Furihata M. Expression of cadherin-17 promotes metastasis in a highly bone marrow metastatic murine breast cancer model. Biomed Res Int 2017;2017:8494286.

97. Bartolomé RA, Aizpurua C, Jaén M, Torres S, Calviño E, et al. Monoclonal antibodies directed against cadherin RGD exhibit therapeutic activity against melanoma and colorectal cancer metastasis. Clin Cancer Res 2018;24:433-44.

98. Zender L, Spector MS, Xue W, Flemming P, Cordon-Cardo C, et al. Identification and validation of oncogenes in liver cancer using an integrative oncogenomic approach. Cell 2006;125:1253-67.

99. Overholtzer M, Zhang J, Smolen GA, Muir B, Li W, et al. Transforming properties of YAP, a candidate oncogene on the chromosome 11q22 amplicon. Proc Natl Acad Sci USA 2006;103:12405-10.

100. Morin-Kensicki EM, Boone BN, Howell M, Stonebraker JR, Teed J, et al. Defects in yolk sac vasculogenesis, chorioallantoic fusion, and embryonic axis elongation in mice with targeted disruption of Yap65. Mol Cell Biol 2006;26:77-87.

101. Zhao B, Ye X, Yu J, Li L, Li W, et al. TEAD mediates YAP-dependent gene induction and growth control. Genes Dev 2008;22:1962-71.

102. Dong J, Feldmann G, Huang J, Wu S, Zhang N, et al. Elucidation of a universal size-control mechanism in Drosophila and mammals. Cell 2007;130:1120-33.

103. Wu H, Liu Y, Jiang XW, Li WF, Guo G, et al. Clinicopathological and prognostic significance of Yes-associated protein expression in hepatocellular carcinoma and hepatic cholangiocarcinoma. Tumour Biol 2016;37:13499-508.

104. Xu MZ, Yao TJ, Lee NP, Ng IO, Chan YT, et al. Yes-associated protein is an independent prognostic marker in hepatocellular carcinoma. Cancer 2009;115:4576-85. 
105. Wang Y, Dong Q, Zhang Q, Li Z, Wang E, et al. Overexpression of yes-associated protein contributes to progression and poor prognosis of non-small-cell lung cancer. Cancer Sci 2010;101:1279-85.

106. Hayashi H, Higashi T, Yokoyama N, Kaida T, Sakamoto K, et al. An imbalance in TAZ and YAP expression in hepatocellular carcinoma confers cancer stem cell-like behaviors contributing to disease progression. Cancer Res 2015;75:4985-97.

107. Lamar JM, Stern P, Liu H, Schindler JW, Jiang ZG, et al. The Hippo pathway target, YAP, promotes metastasis through its TEADinteraction domain. Proc Natl Acad Sci U S A 2012;109:E2441-50.

108. Zhou Z, Hu T, Xu Z, Lin Z, Zhang Z, et al. Targeting Hippo pathway by specific interruption of YAP-TEAD interaction using cyclic YAP-like peptides. FASEB J 2015;29:724-32.

109. Gibault F, Coevoet M, Sturbaut M, Farce A, Renault N, et al. Toward the discovery of a novel class of YAP-TEAD interaction inhibitors by virtual screening approach targeting YAP-TEAD protein-protein interface. Cancers (Basel) 2018;10:E140.

110. Guerra E, Trerotola M, Aloisi AL, Tripaldi R, Vacca G, et al. The Trop-2 signalling network in cancer growth. Oncogene 2013;32:1594-600.

111. Fong D, Moser P, Krammel C, Gostner JM, Margreiter R, et al. High expression of TROP2 correlates with poor prognosis in pancreatic cancer. Br J Cancer 2008;99:1290-5.

112. Fong D, Spizzo G, Gostner JM, Gastl G, Moser P, et al. TROP2: a novel prognostic marker in squamous cell carcinoma of the oral cavity. Mod Pathol 2008;21:186-91.

113. Mühlmann G, Spizzo G, Gostner J, Zitt M, Maier H, et al. TROP2 expression as prognostic marker for gastric carcinoma. J Clin Pathol 2009;62:152-8.

114. Ning S, Guo S, Xie J, Xu Y, Lu X, et al. TROP2 correlates with microvessel density and poor prognosis in hilar cholangiocarcinoma. J Gastrointest Surg 2013;17:360-8.

115. Ohmachi T, Tanaka F, Mimori K, Inoue H, Yanaga K, et al. Clinical significance of TROP2 expression in colorectal cancer. Clin Cancer Res 2006;12:3057-63.

116. Liu T, Liu Y, Bao X, Tian J, Liu Y, et al. Overexpression of TROP2 predicts poor prognosis of patients with cervical cancer and promotes the proliferation and invasion of cervical cancer cells by regulating ERK signaling pathway. PLoS One 2013;8:e75864.

117. Bignotti E, Todeschini P, Calza S, Falchetti M, Ravanini M, et al. Trop-2 overexpression as an independent marker for poor overall survival in ovarian carcinoma patients. Eur J Cancer 2010;46:944-53.

118. Chen MB, Wu HF, Zhan Y, Fu XL, Wang AK, et al. Prognostic value of TROP2 expression in patients with gallbladder cancer. Tumour Biol 2014;35:11565-9.

119. Lin H, Huang JF, Qiu JR, Zhang HL, Tang XJ, et al. Significantly upregulated TACSTD2 and Cyclin D1 correlate with poor prognosis of invasive ductal breast cancer. Exp Mol Pathol 2013;94:73-8.

120. Gui T, Dong X, Li R, Li Y, Wang Z. Identification of hepatocellular carcinoma-related genes with a machine learning and network analysis. J Comput Biol 2015;22:63-71.

121. Ikeda Y, Imai Y, Kumagai H, Nosaka T, Morikawa Y, et al. Vasorin, a transforming growth factor beta-binding protein expressed in vascular smooth muscle cells, modulates the arterial response to injury in vivo. Proc Natl Acad Sci USA 2004;101:10732-7.

122. Chen L, Yao JH, Zhang SH, Wang L, Song HD, et al. Slit-like 2, a novel zebrafish slit homologue that might involve in zebrafish central neural and vascular morphogenesis. Biochem Biophys Res Commun 2005;336:364-71.

123. Li S, Li H, Yang X, Wang W, Huang A, et al. Vasorin is a potential serum biomarker and drug target of hepatocarcinoma screened by subtractive-EMSA-SELEX to clinic patient serum. Oncotarget 2015;6:10045-59.

124. Cao DX, Li ZJ, Jiang XO, Lum YL, Khin E, et al. Osteopontin as potential biomarker and therapeutic target in gastric and liver cancers. World J Gastroenterol 2012;18:3923-30.

125. Kim J, Ki SS, Lee SD, Han CJ, Kim YC, et al. Elevated plasma osteopontin levels in patients with hepatocellular carcinoma. Am J Gastroenterol 2006;101:2051-9.

126. Shang S, Plymoth A, Ge S, Feng Z, Rosen HR, et al. Identification of osteopontin as a novel marker for early hepatocellular carcinoma. Hepatology 2012;55:483-90.

127. Sun T, Tang Y, Sun D, Bu Q, Li P. Osteopontin versus alpha-fetoprotein as a diagnostic marker for hepatocellular carcinoma: a metaanalysis. Onco Targets Ther 2018;11:8925-35.

128. Fouad SA, Mohamed NA, Fawzy MW, Moustafa DA. Plasma osteopontin level in chronic liver disease and hepatocellular carcinoma. Hepat Mon 2015;15:e30753.

129. Sun T, Li P, Sun D, Bu Q, Li G. Prognostic value of osteopontin in patients with hepatocellular carcinoma: A systematic review and meta-analysis. Medicine (Baltimore) 2018;97:e12954.

130. Liu K, Duan J, Liu H, Yang X, Yang J, et al. Precancer antiviral treatment reduces microvascular invasion of early-stage Hepatitis B-related hepatocellular carcinoma. Sci Rep 2019;9:2220.

131. Sun BS1, Dong QZ, Ye QH, Sun HJ, Jia HL, et al. Lentiviral-mediated miRNA against osteopontin suppresses tumor growth and metastasis of human hepatocellular carcinoma. Hepatology 2008;48:1834-42.

132. Shojaei F, Scott N, Kang X, Lappin PB, Fitzgerald AA, et al. Osteopontin induces growth of metastatic tumors in a preclinical model of non-small lung cancer. J Exp Clin Cancer Res 2012;31:26.

133. Dai J, Li B, Shi J, Peng L, Zhang D, et al. A humanized anti-osteopontin antibody inhibits breast cancer growth and metastasis in vivo. Cancer Immunol Immunother 2010;59:355-66.

134. Lim WA, June CH. The principles of engineering immune cells to treat cancer. Cell 2017;168:724-40.

135. Kershaw MH, Westwood JA, Parker LL, Wang G, Eshhar Z, et al. A phase I study on adoptive immunotherapy using gene-modified T cells for ovarian cancer. Clin Cancer Res 2006;12:6106-15.

136. Lamers CH, Sleijfer S, van Steenbergen S, van Elzakker P, van Krimpen B, et al. Treatment of metastatic renal cell carcinoma with CAIX CAR-engineered T cells: clinical evaluation and management of on-target toxicity. Mol Ther 2013;21:904-12. 
137. Morgan RA, Yang JC, Kitano M, Dudley ME, Laurencot CM, et al. Case report of a serious adverse event following the administration of T cells transduced with a chimeric antigen receptor recognizing ERBB2. Mol Ther 2010;18:843-51.

138. van den Berg JH, Gomez-Eerland R, van de Wiel B, Hulshoff L, van den Broek D, et al. Case report of a fatal serious adverse event upon administration of T cells transduced with a MART-1-specific T-cell receptor. Mol Ther 2015;23:1541-50.

139. Gupta S, Bent S, Kohlwes J. Test characteristics of $\alpha$-fetoprotein for detecting hepatocellular carcinoma in patients with hepatitis C: A systematic review and critical analysis. Ann Intern Med 2003;139:46-50.

140. Shaheen KY, Abdel-Mageed AI, Safwat E, AlBreedy AM. The value of serum midkine level in diagnosis of hepatocellular carcinoma. Int J Hepatol 2015;2015:146389.

141. Giannelli G, Fransvea E, Trerotoli P, Beaugrand M, Marinosci F, et al. Clinical validation of combined serological biomarkers for improved hepatocellular carcinoma diagnosis in 961 patients. Clin Chim Acta 2007;383:147-52.

142. Sun Y, Gao G, Cai J, Wang Y, Qu X, et al. Annexin A2 is a discriminative serological candidate in early hepatocellular carcinoma. Carcinogenesis 2013;34:595-604.

143. Chounta A, Ellinas C, Tzanetakou V, Pliarhopoulou F, Mplani V, et al. Serum soluble urokinase plasminogen activator receptor as a screening test for the early diagnosis of hepatocellular carcinoma. Liver Int 2015;35:601-7. 